\title{
El marxismo político, excéntrico, heterodoxo, radical y sin ismos de un epistemólogo comunista que amaba "La flauta mágica"
}

\author{
The political, excentric, unorthodox, radical and \\ without -isms marxism of a communist epistemologist \\ who loved "The magic flute"
}

\author{
SALVADOR LÓPEZ ARNAL
}

UNED e IES Puig Castellar de Santa Coloma de Gramenet (Barcelona)

\begin{abstract}
RESUMEN. Manuel Sacristán Luzón (1925-1985), un lógico, epistemólogo y filósofo heterodoxo, militante del PSUC-PCE durante largos años, que tuvo un papel esencial en la reintroducción de la tradición marxista-comunista en nuestro país a finales de los años cincuenta, sugirió en sus últimos años una fuerte revisión del ideario comunista tras el Mayo del 68, la aniquilación de la Primavera de Praga y, destacadamete, la irrupción de las problemáticas ecológicas. Sus propuestas para una política de la ciencia de orientación socialista, próxima a la tradición tecnocientífica no cegada y crítica a un tiempo de las concepciones neorrománticas inspiradas en la obra de Heidegger (sobre cuya gnoseología escribió su tesis doctoral), siguen siendo muestra de la lucidez y penetración de un pensamiento nunca servil ni agotado que apostó siempre por una pasión (emancipatoria) razonada anclada en la información científica contrastada, en el compromiso con los desfavorecidos de la tierra y en la práctica de un filosofar creativo y humanista.
\end{abstract}

Palabras clave: Marxismo crítico, comunismo, ecologismo, tradición emancipatoria, Primavera de Praga, Mayo del 68, investigación básica, dialéctica, lysenkismo, Manifiesto Comunista, AntiDühring, F. Fernández Buey, A.Gramsci, M. Heidegger, J. Mosterín.
AbSTRaCt. Manuel Sacristán Luzón (19251985) was a logician, epistemologist and unorthodox philosopher -PSUC-PCE militant during many years- who had an essential role in the reintroduction of the Marxist-communist tradition in our country at the end of the fifties. He proposed, during the last years of his life, a strong revision of the communist ideology after May 68 and the annihilation of the Prague Spring. He also concentrated on the irruption of environmentalism. His proposals for a politics of science oriented in a socialist way, and close to the technoscientific tradition which is not blind but which is critical of the new romantic conceptions inspired in the work of Heidegger -about whose gnoseology he wrote his doctoral thesis- are still proof of the lucidity and penetration of his thought. He always fought for an (emancipatory) passion that is anchored in reason and in scientific information, in the commitment towards the most disadvantaged groups in the Earth, and in the practice of a creative and humanist philosophy.

Key words: Critical Marxism, communism, environmentalism, emancipatory tradition, Prague Spring, May 68, basic research, dialectics, Lysenkoism, Communist Manifesto, Anti-Dühring, F. Fernández Buey, A.Gramsci, M. Heidegger, J. Mosterín. 
Para Manuel Sacristán, Giulia Adinolfi,

Francisco Fernández Buey y Neus Porta. In memoriam et ad honorem

No es nada entusiasmante (el éxito en la vida según la concepción occidental dominante) para seguir adelante. Prefiero un fracaso honrado, claro, y sin opresión ni agresión.

Manuel Sacristán (1980)

"Puede decirse, para concluir, que la reflexión iniciada por Manuel Sacristán en 1968 y continuada prácticamente hasta su muerte, en 1985, es una reconsideración única del programa comunista, una reconsideración que no tiene apenas similitud con ninguna otra de las iniciadas durante esa época. El proyecto de Sacristán no puede identificarse ni con una rendición incondicional al fundamentalismo liberal que representó el "eurocomunismo", ni con la atracción por el populismo maoísta a la europea, ni con las recuperaciones añorantes del izquierdismo mecanicista de la III Internacional, ni con el prosovietismo, ni con el trotskismo. Tampoco hizo nunca Sacristán concesiones a ninguna de estas corrientes (con las que, sin embargo, dialogó siempre considerando que eran parte de una misma tradición cultural); razón por la cual todavía ahora [1995] su evolución durante aquellos años suele ser mal comprendida en España. Su marxismo fue incómodo en la época del resurgimiento del marxismo. Y lo siguió siendo en la época de la "crisis del marxismo".

Así se expresaba Francisco Fernández Buey en "El marxismo crítico de Manuel Sacristán", un artículo escrito como homenaje a su amigo en el décimo aniversario de su fallecimiento. En mi opinión, el mejor texto publicado hasta el momento sobre este aspecto esencial de la obra político-filosófica de Sacristán. El objetivo de esta nota es explicar y desarrollar algunos vértices de ese texto referenciado que he tomado como guía.

\section{Un marxista con pensamiento propio.}

Sacristán nunca practicó la hagiografía en su relación con los grandes nombres del marxismo. La dialéctica engelsiana, la noción de ciencia en la obra marxiana y su proyecto antiideológico, el concepto de filosofía y del filosofar en la tradición, la categoría gramsciana de ideología, la concepción lukácsiana de racionalidad, el ecologismo comunista de Harich, el papel de los intelectuales en los partidos comunistas en diálogo con Togliatti (uno de sus grandes referentes políticos), el pacifismo antimilitarista de Thompson, la praxeología, el estatuto epistemológico de $\mathrm{El} \mathrm{Ca}$ pital, el utopismo neorromántico de Marcuse, son ejemplos de todo ello.

Lo hizo, además, con la libertad de pensamiento que era marca destacadísima de su obra y acción. Una ilustración de esto último. Una conferencia impartida en la Universidad Autónoma de Barcelona en abril de 1970 sobre el filosofar de Lenin, posteriormente prólogo de la edición castellana de $M a$ terialismo y empiriocriticismo, se iniciaba, por alguien que era considerado entonces un marxista-leninista ortodoxo-dogmático, con las siguientes palabras:

La insuficiencia técnica o profesional de los escritos filosóficos de Lenin salta a la vista del lector. Para ignorarla hacen falta la premeditación del demagogo o la oscuridad del devoto ${ }^{2}$. 
Él no fue un devoto y su cultivo de la tradición nunca fue asunto meramente académico. El marxismo político que practicó siempre tuvo muy en cuenta "el buen sentir chiricahua" del que él mismo habló en una de sus anotaciones a la biografía del indio Gerónimo. También el suyo se expresaba en el hacer, por eso fue muy sensible a los grandes acontecimiento de la época.

Sus preocupaciones políticas, culturales y filosóficas más esenciales giraron en la búsqueda de revisiones y cambios sustantivos tras el doble aldabonazo (las consecuencias del Mayo de 1968 y la aniquilación de la primavera de Praga), la derrota de la Unidad Popular y el triunfo del fascismo en Chile, y la fuerte irrupción de la problemática ecológica después de los primeros informes sobre los efectos negativos y ecosuicidas del desarrollismo industrial descontrolado. El eurocomunismo o el compromiso histórico siempre fueron vistos por él como una ilusión, y no siempre heroica. Como el viejo Lukács, también creyó que era necesario volver a empezar en numerosos ámbitos. Fernández Buey ha explicado con sentidas palabras lo que para Sacristán significó lo acontecido en Chile ${ }^{3}$ :

La tragedia del socialismo en Chile, en 1973, afectó a Manolo profundamente. No escribió sobre eso porque le deprimió todo lo que estaba pasando: la confusión generalizada entre estar en el gobierno y tener el poder, la forma en que se produjo el golpe de Estado y la reacción de las direcciones de los partidos comunistas europeos.

El análisis de la experiencia del país hermano, concluye el autor de La gran perturbación, le reafirmó en su convicción de que había que pensar casi todo de nuevo. Había que pintar la pizarra del presente bien negra para que resaltase sobre ella el blanco de la tiza con el que había que dibujar las nuevas alternativas. Sacristán habló a partir de entonces de nuevos problemas, de problemas post-leninistas, y de nuevos procedimientos. Irrumpieron en su obra, escrita en condiciones muy difíciles (la clandestinidad durante dos décadas, su expulsión de la Universidad a la que sólo pudo volver de forma continuada en 1976, la oposición de 1962 a la cátedra de lógica de Valencia), nuevas categorías y desarrollos teórico-políticos que alimentaron en ocasiones movimientos sociales críticos y alternativos.

Sacristán fue un pensador y un activista que intentó complementar conocimiento científico y pasión poliética con la intención de servir a los comunes, a los desfavorecidos, a los explotados de la Tierra. Contra corriente. Cuando el marxismo de los sesenta andaba más que sobrado de palabrería insulsa y se alejada años-luz de la ciencia y el conocimiento contrastado, hablando engreídamente y desde abismos de ignorancia desconocida de ciencia de clase y lógicas fijistas, el traductor de Quine y Taton ponía énfasis en la metodología, en la argumentación racional, en la importancia de la lógica formal, en la filosofía de la ciencia y en la conveniencia cuanto no necesidad de saber ciencia, la máxima posible. Cuando el marxismo de los setenta y parte de los ochenta, apostaba por el cientificismo (no siempre por la ciencia real), el autor de Intervenciones políticas ponía énfasis en la pasión razonada, en la dimensión poliética, en el trabajo voluntario de los militantes, en la importancia de la organiza- 
ción de los de abajo, en los movimientos sociales no asimilados, en la práctica revolucionaria que no pierde de vista los grandes objetivos y abona grandes esperanzas. La esencia del programa del Sacristán tardío la apuntó él mismo en el editorial del primer número de mientras tanto, la revista que más hizo suya:

Aunque convencidos de que las contradicciones entonces aludidas [editorial del primer número de Materiales] se han agudizado, sin embargo, ahora nos sentimos un poco menos perplejos (lo que no quiere decir más optimistas) respecto de la tarea que habría que proponerse para que tras esta noche oscura de la crisis de una civilización despuntara una humanidad más justa en una Tierra habitable, en vez de un inmenso rebaño de atontados ruidosos en un estercolero químico, farmacéutico y radiactivo.

La tarea, que no podía cumplirse con agitada veleidad irracionalista sino teniendo racionalmente sosegada la casa de la izquierda, consistía en renovar la alianza ochocentista del movimiento obrero con la ciencia.

Puede que los viejos aliados tengan dificultades para reconocerse, pues los dos han cambiado mucho: la ciencia, porque desde la sonada declaración de Emil Du Bois Reymond -ignoramus et ignorabimus, ignoramos e ignoraremos-, lleva ya asimilado un siglo de autocrítica (aunque los científicos y técnicos siervos del estado atómico y los lamentables progresistas de izquierda obnubilados por la pésima tradición de Dietzgen y Materialismo y Empiriocriticismo no parezcan saber nada de ello); el movimiento obrero, porque los que viven por sus manos son hoy una humanidad de complicada composición y articulación.

La tarea se podía ver de varios modos, según el lugar desde el que se la emprendiera. Se trataba de conseguir que los movimientos ecologistas, que estaban entre los portadores de la ciencia autocrítica de aquellas décadas, se dotaran de capacidad revolucionaria.

\section{Marxismo y comunismo.}

En un artículo de encargo que el autor de Sobre Marx y marxismo escribió para el suplemento de la Enciclopedia Labor de $1968^{4}$, y tras señalar que la expresión filosofía marxista era confusionaria y hasta probablemente errónea si se refería a los dos grandes clásicos de la tradición en la medida "en que podría serlo la expresión filosofía neopositivista", Sacristán destacaba un punto central de su forma de comprender la tradición marxista y engelsiana:

El autor de este artículo, por su parte, ha negado que pueda hablarse de filosofía marxista en el sentido sistemático tradicional de filosofía, sosteniendo que el marxismo debe entenderse como otro tipo de hacer intelectual, a saber, como la conciencia critica del esfuerzo por crear un nuevo mundo humano.[la cursiva es mía].

Años después, en la que fuera una de las entrevistas que se le hicieron de mayor calado filosófico, el profesor de Metodología de las Ciencias Sociales apuntaba que, en su opinión, se encontraba el camino ra- 
cional de interpretación de la obra marxiana si se abandonaba "el prurito apologético" y se estudiaba al revolucionario de Tréveris en su momento histórico, lo que podía y debía hacerse sabiendo que había un aspecto de su obra "tan incaducable como el Nuevo Testamento o la poesía de Garcilaso". El director de mientras tanto se refería a las aportaciones de Marx como filósofo del socialismo, como creador y clarificador de valores socialistas. Del mismo modo, debíamos desprendernos también de los restos de lo que llamaba zdhanovismo o lysenkismo. Se debía dejar de confundir la génesis de un producto cultural y su posible validez. No se trataba "de tomar en bloque la filosofía de la ciencia como una doctrina verdadera o falsa, sino como un campo de investigación nada superfluo" que era necesario cultivar porque era "un prejuicio oscurantista sostener que porque se ha originado en esta fase de la cultura capitalista no ha de tener validez alguna".

El marxismo-comunismo de Sacristán, su filosofía de la praxis de inspiración gramsciana, revisó conceptos, ámbitos de intervención y finalidades esenciales al compás de una de las mayores tragedias del comunismo político del siglo XX: la invasión de Checoslovaquia por las tropas del Pacto de Varsovia en agosto de 1968. Lo esencial de lo sucedido lo expresó en una carta que escribió cuatro días después de la infame aniquilación de aquella esperanzadora primavera del comunismo democrático, reflexión a la que al año siguiente añadía, con clarividencia, en una entrevista para Cuadernos para el Diálogo, que veríamos además cosas peores, mucho peores. No erró, no se equivocó.

La carta a la que hacemos referencia, dirigida a Xavier Folch, entonces compa- ñero de Partido y de trabajos editoriales, decía así ${ }^{5}$ :

Tengo que bajar a Barcelona el jueves día 29 ... Tal vez porque yo, a diferencia de lo que dices de ti, no esperaba los acontecimientos, la palabra "indignación" me dice poco. El asunto me parece lo más grave ocurrido en muchos años, tanto por su significación hacia el futuro cuanto por la que tiene respecto de cosas pasadas. Por lo que hace al futuro, me parece síntoma de incapacidad de aprender. Por lo que hace al pasado, me parece confirmación de las peores hipótesis acerca de esa gentuza, confirmación de las hipótesis que siempre me resistí a considerar. La cosa, en suma, me parece final de acto, si no ya final de tragedia. Hasta el jueves

Lo sucedido, en el momento en que estaba finalizando su Antología de Gramsci y su detallada (y finalmente interrumpida) presentación, El orden y el tiempo, le llevó a una reconsideración radical de numerosos nudos de su tradición revolucionaria.

\section{Para leer el Manifiesto Comunista.}

No se conserva ninguna cinta ni se han encontrado apuntes de la conferencia que, según testimonio de Jaume Botey, impartió Sacristán en la Escuela de alfabetización de adultos de Can Serra (l'Hospitalet de Llobegat, Barcelona) a mediados de los años setenta sobre el Manifiesto Comunista. Se conservan, eso sí, copias de un escrito titulado "Para leer el Manifiesto del Partido Comunista. Plan de estudios elemental. Curso primero" datado en 1956 o 1957. Discutido con Giulia Adinolfi y Pilar Fibla, fue editado pos- 
teriormente ( $\sin$ firma obviamente) por el comité ejecutivo del PSUC en febrero de $1972^{6}$. Escrito para ser discutido entre militantes y simpatizantes del Partido, muestra bien a las claras el rigor filosófico de su autor, su libertad de lectura nunca abandonada, su interpretación nunca talmúdica de los grandes textos de la tradición. Un resumen que ilustra esas características:

Sacristán inicia el texto con una reflexión sobre la necesidad que sienten grupos de trabajadores de mejorar su formación teórica con el estudio del pensamiento marxista. En su opinión, "satisfacer esta necesidad exige en primer lugar la práctica, aprender de la lucha”. Pero también exigía trabajo de estudio, tarea que tenía que ser primero individual: "intentar "ponerse de codos" sobre los libros". El posterior trabajo colectivo en círculos de estudio podía resultar muy útil al menos por dos razones: "1 1 , porque da la costumbre de estudiar a quienes no la tienen, $2^{\mathrm{a}}$ porque con las opiniones de muchos se precisa y enriquece el pensamiento de cada uno".

El material está dividido en tres apartados. En el primero, Sacristán da cuenta de por qué no le parecen recomendables manuales de introducción escritos por marxistas para "basar un plan de estudios elemental". Todo manual resulta de "una interpretación, que prescinde de cosas, recoge otras y pone a éstas en un determinado orden". Los manuales de aquella época estaban "concebidos como si no existiera nunca ningún problema de interpretación de los clásicos, ni necesidad de atender a nuevas realidades". En ellos se introducían divisiones que no estaban propiamente en los clásicos. La que dividía al marxismo en materialismo dialéctico (expresión que él apenas usó) y en materialismo histórico por ejemplo. Esas cla- sificaciones acabaron por convertir "el marxismo en una escolástica catequística”. Sacristán señalaba finalmente que tanto Marx como Engels consideran muerta la filosofía en el sentido de sistema, como teoría cuya finalidad gnoseológica central fuera la explicación del Todo. Los manuales existentes eran precisamente filosofía "en ese sentido escolástico extraño al marxismo".

Entre los escritos de los clásicos existían dos obras que tenían las características que hacían "del manual un instrumento útil para aprender a hacer o pensar algo: son breves repasos de muchos temas". Estaba hablando del Anti-Dühring, que él mismo tradujo y prologó ${ }^{7}$, y del Manifiesto Comunista [MC]. No eran la solución perfecta -el Manifiesto tenía entonces más de un siglo de antigüedad- pero eran un mal menor.

El segundo apartado está centrado en el MC, a cuyo estudio debería dedicarse la primera parte de un curso elemental. Si en el prólogo de 1872 Marx y Engels ya sostenían el carácter caduco de algunas de las partes del escrito, mucho más lo serían casi un siglo después. El MC había sido escrito por encargo de la Liga de Comunistas, "una organización clandestina formada sobre todo por emigrados alemanes en Francia”. Dada la influencia que entre los obreros franceses tenía el socialismo utópico, Marx y Engels habían dedicado varias páginas a la crítica de diversas tendencias del socialismo. Sacristán recordaba que, en aquel entonces, las ideas de la Liga eran poco precisas, que el propio Marx aún no había elaborado su teoría de la plusvalía y que muchos miembros de la Liga eran de tendencia anarquista. De ahí que en el MC faltaran ideas marxianas centrales y que, además, tuviera pasajes ambiguos con la buscaba finalidad "de que los 
miembros de tendencias anarquistas aprobaran el escrito".

El segundo apartado finalizaba con unas indicaciones pedagógicas. La lectura del texto debía ser individual. En la primera fase del estudio colectivo, un miembro del grupo resumiría una parte o la totalidad de un capítulo. Los restantes compañeros criticarían, completarían o aprobarían la lectura anterior. La finalidad de esta fase era "asegurarse de que se ha llegado a una interpretación textual en la que esté de acuerdo todo el grupo de estudio...". Finalmente, se discutirían las cuestiones de fondo. Es decir, no "¿qué es lo que dice el texto?" sino "¿es verdad lo que dice el texto?".

La sección III señalaba posibles puntos para la discusión. Estaba dividida en tres apartados: "cuestiones teóricas generales", "análisis de la sociedad capitalista y su evolución" y "toma y ejercicio del poder por la clase obrera. Sociedad comunista".

En el primero de estos apartados, se discutían temas como los siguientes:

1. El papel de los factores sobrestructurales. Sacristán señalaba que sobre este tema la dificultad era precisar qué se quería decir cuando se afirmaba que "la vida política y cultural se construye sobre la base económico-social". Si lo afirmado apuntara a que todo elemento político-cultural venía, directa o indirectamente, de la base económicosocial, ningún elemento sobreestructural tendría entonces influencia en la base económica. La tesis estaría refutada en el propio MC. Dos eran los hechos citados en él, de carácter sobreestructural, que habían influido en la marcha de la economía burguesa: el descubri- miento de América y la circunnavegación de África.

2. El comunismo primitivo. La tesis de la historia entendida como lucha de clases había sido modificada en unos de los prólogos del MC: se exceptuaba de ella el llamado "comunismo primitivo". Las cuestiones que valía la pena discutir eran entonces: a) ¿qué validez tenía la hipótesis del comunismo primitivo en la ciencia prehistórica, la antropología y la etnología de aquellos momentos?; b) la observación de que la introducción de esa nueva hipótesis sólo les había hecho modificar a Marx y a Engels su concepción de la prehistoria humana, no su visión de la historia propiamente dicha.

3. La alienación. En el capítulo III del MC se rechaza "la consideración filosófica de los problemas sociales o básicos". De este modo se marginaba el delicado asunto de la alienación ${ }^{8}$. El tema había sido ampliamente discutido entre marxistas. Para unos, era un simple resto idealista-hegeliano; para otros, era un punto esencial del marxismo. Para él, la situación del tema en los textos clásicos era la siguiente: antes del MC, Marx había hablado de alienación en el sentido de que "el hombre ha estado siempre sometido, como si fueran fuerzas autónomas, a cosas que él mismo crea". Ideas religiosas, ideales morales, concepciones jurídicas, etc. eran producto suyo pero las consideraba poderes externos a él. En el MC, Marx se desentendía de este tipo de consideraciones filosóficas generales. Después del MC, Marx hablaba de un fenómeno por él descubierto, "el fetichismo de la mercancía". Cuando un producto producido por el ser humano pasaba al mercado, cobraba en él un va- 
lor de cambio que era un valor abstracto. El valor de cambio, llamado mercancía, no era idéntico a su valor de uso. La mercancía a pesar de ser un producto de seres humanos "está regida por leyes que son independientes de la voluntad de sus productores y de sus consumidores, y a menudo contrarias a dicha voluntad". En la sociedad capitalista, donde todo se mercantilizaba, el producto humano, convertido en mercancía, se hacía "fetiche": "como el fetiche, la mercancía está producida por el hombre, pero el hombre se somete a ella como el primitivo al fetiche". En sus últimos años, Marx y Engels sostuvieron que la sociedad comunista no causará la fetichización de los productos, ni el fetichismo generalizado causado por la economía y la sociedad capitalistas. La posición de Sacristán en esta temática contradecía, por tanto, la de otros marxistas que sostenían que el tema de la alienación era un mero resto hegeliano-idealista en la obra de Marx, una cuestión no propiamente marxista o, cuanto menos, inexistente en el Marx más maduro, en el "propiamente científico".

En el apartado B del material, "Análisis de la sociedad capitalista y de su evolución”, Sacristán señalaba algunas insuficiencias del MPC respecto a la situación y evolución de la sociedad capitalista a mediados de nuestro siglo breve. Se discutían aquí temas como los siguientes:

1. ¿Dos clases únicas? ¿Existe una tercera clase entre la burguesía y el proletariado? Su posición la resumía así:

[...] una cosa es que con la gran industria capitalista y su evolución sea naturalmente compatible una industria artesana - cuyos miembros forman efectivamente una clase media entre el proletariado y la clase capitalista-; y otra cosa es que con la gran industria capitalista y su evolución sean compatibles industrias pequeñas o menores, pero también capitalistas- en cuyo caso no hay tercera clase...

2. El Estado burgués como administrador de los intereses de la burguesía. Sugería en este punto temas del siguiente tenor: ¿la lucha de la clase obrera había perturbado esa función del estado burgués? ¿Era impedida esa función por la división misma de la burguesía en capas y grupos de interés?

3. El cambio en la sociedad burguesa. Clarificaba en este punto la tesis del $\mathrm{MC}$ según la cual era característico de la sociedad burguesa un rápido cambio en la producción misma. ¿Era contradictoria esa afirmación con la tesis básica del Manifiesto que sostenía que un cambio en las relaciones de producción era un cambio de toda la base social? Su respuesta era negativa: "cada clase sigue en la misma relación en que estaba con los medios de producción". Lo característico del capitalismo es que se producen en él muchas más innovaciones técnicas que en otros anteriores modos de producción.

La última parte del escrito estaba dedicada al tema del poder político. Señalaba aquí Sacristán que en el MC Marx y Engels no indicaban nada sobre "la toma del poder por la clase obrera y muy poco acerca del ejercicio del mismo". Hablarán posteriormente de un cambio total de la organización del Estado a partir de 1871, en base a la experiencia de la Comuna de París. Respecto a 
la familia, la moral y la cultura, Sacristán sostenía que la sociedad comunista debía desfetichizar completamente esas relaciones, liberarlas de todo carácter no-personal $\mathrm{y}$ hacerlas libres y puramente humanas. El MC, advertía, era oscuro en este punto. Por dos razones: para ser aceptado por los miembros anarquistas de la Liga y por falta de elaboración. Así, el Manifiesto presentaba "al proletariado desligado del pasado cultural", como si no tuviera nada que ver "con las conquistas conseguidas por la humanidad bajo el dominio de otras clases (piénsese, por ejemplo, en la ciencia)".

\section{Leer con ojos indagadores.}

Desde sus primeros escritos, Sacristán tuvo una visión singular de lo que era el cultivo de los clásicos, de la forma en que una tradición política revolucionaria con una singular arista filosófica, como era el marxismo, debía cultivar las aportaciones de sus grandes autores.

En 1964, con ocasión de su prólogo a la traducción castellana del Anti-Dühring, Sacristán señalaba que un clásico -y citada como ejemplo a Euclides- no era, para los hombres que cultivaban su ciencia, más que una fuente de inspiración que definía, "con mayor o menor claridad, las motivaciones básicas de su pensamiento". Los clásicos del movimiento obrero habían señalado, además de unas motivaciones intelectuales, los fundamentos del movimiento, sus objetivos más generales. Los clásicos marxistas eran ante todo clásicos de una cosmovisión, no de una teoría científico-positiva determinada, lo que originaba una relación de adhesión militante entre ellos y el movimiento. Ello ocasionaba de forma "bastante natural que la perezosa tendencia a no ser crítico, a no preocuparse más que de la propia seguridad moral, práctica" se impusiera frecuentemente en la lectura atenta de esos clásicos, con un riesgo de alto voltaje que no había que perder de vista: el peligro de consagrar cualquier estado histórico de la teoría "con la misma intangibilidad que tienen para un movimiento político-social los objetivos programáticos que lo definen". Si a ello se le sumaba que la lucha contra el marxismo mezclaba la crítica de desarrollos teóricos caducados con la alteración de sus objetivos, se comprendía entonces, señalaba, "por qué una lectura perezosa y dogmática de los clásicos del marxismo ha tenido hasta ahora la partida fácil. Y la partida fácil se convirtió en partida ganada por la simultánea coincidencia de las necesidades de divulgación -siempre simplificadora- con el estrecho aparato montado por Jdhanov y Stalin para la organización de la cultura marxista".

Tres años más tarde, escribía una reseña sobre Lenin, un ensayo escrito por Roger Garaudy en su etapa marxista, que había sido publicado en Francia en 1967 en la serie "filósofos" de PUF, una colección destinada al uso didáctico en el bachillerato y en la iniciación universitaria. El responsable del PSUC publicó su trabajo en Nous Horitzons ${ }^{9}$, la revista teórica del PSUC, de la que él mismo llegó a ser director entre 1967 y 1970. Señalaba en su nota que, a pesar de la brevedad, el libro merecía atención por provenir de un escritor marxista entonces tan sincero y leído como Garaudy, y apuntaba la idea de que la gravedad de los problemas con los que se enfrentaba entonces el movimiento comunista revelaban con claridad la inutilidad de la literatura marxista inauténtica, es decir, la de "tantos tratados y manuales con to- 
dos los problemas del mundo resueltos". Por ello, la lectura de escritores marxistas que verdaderamente pensaran, nos gustara o no lo que pensaran, era "recomendable incluso como ejercicio político". Como Althusser, Garaudy podía haber sucumbido en otros momentos a la "línea imperativa", es decir, a la idea partidista según la cual la filosofía marxista no podía elegir sino entre el comentario y el silencio, "una convicción iluminada o bien obligada y al mutismo del malestar. Pero hay mudos y mudos, y Garaudy, como su contrincante Althusser, pertenecía ya entonces a la clase de mudos que podían hablar porque saben pensar".

El breve volumen sobre Lenin tenía, en su opinión, dos rasgos que convenía destacar: Garaudy no mostraba en su trabajo el excesivo respeto por las definiciones tradicionales que era frecuente en la literatura francesa, incluso en la marxista, $y$, por otra parte, Sacristán destacaba la manera de construir los aspectos del pensamiento de Lenin que Garaudy ofrecía en su estudio, acentuando sobre todo la insistencia del revolucionario soviético en la importancia del factor subjetivo en la historia y sus enérgicas tomas de posición antidogmáticas y antisectarias en diversos textos leninistas. Las setenta páginas del ensayo dejaban muy claro que su autor lo había escrito con el fin de librar una batalla en dos frentes: subrayando la importancia del factor subjetivo en el pensamiento de Lenin (contra el derechismo de tipo tradicional) y mostrando que Lenin quería pensar siempre de manera antidogmática y antisectaria (contra el infantilismo o izquierdismo). Ambas cosas le servían, además, "contra el burocratismo y el estatalismo de la degeneración socialista, la cual presenta al mismo tiempo el mecanicismo y la razón de Estado y un sectarismo hipócritamente dogmático que disfraza de teoría, desde los tiempos de Zdanov, lo que es mera implicación del poder o de la lucha por éste en tal o cual intriga momentánea".

En opinión de Sacristán, aquí se planteaba el nudo central de la cuestión: no parecía que la mejor manera de oponerse al derechismo y al nuevo izquierdismo, al igual a que a la degeneración del poder socialista, fuera

[...] continuar utilizando los clásicos del movimiento socialista convirtiéndolos en instrumentos de la disputa. Parece claro que Garaudy tiene razón en su triple polémica, pero parece dudoso que esta razón vaya a triunfar substancialmente con los mismos procedimientos que ha llevado al derechismo "filológico" de la vieja social-democracia (hecha de citas a pie de página de algunos elementos de El Capital), al infantilismo (hecho de citas a pie de página del ¿Qué hacer?, etc) y a la degeneración burocrática revestida con todas las citas, sean de donde sean, que vayan bien para expulsar a alguien, justificar tal ley o proclamar tal sentencia).

De ahí que Sacristán concluyera algo que fue decisivo en su práctica como teórico y filólogo marxista y como divulgador y formador: la necesidad de dejar vivir a los clásicos de una vez, y de no enseñar a citarlos sino a leerlos.

Del mismo modo, entrevistado en 1977 con ocasión de una conferencia que impartió en la Universidad de Barcelona sobre Gramsci, Sacristán señaló una característica para él central del filósofo de la praxis y, en general, de la obra de cualquier au- 
tor que consideremos clásico de una tradición política o filosófica: "Gramsci es un clásico, o sea, un autor que tiene derecho a no estar de moda nunca y a ser leído siempre. Y por todos". Nadie tenía derecho a meterse la obra de un autor clásico en el depósito de su coche para consumo propio y exclusivo.

Sacristán realizó prácticamente lo que fue su aspiración declarada: enseñó a varias generaciones de estudiantes y de militantes a leer sin anteojeras ni prejuicios a algunos de los grandes de la filosofía contemporánea. En uno de sus textos, "El filosofar de Lenin"10, apuntaba lo que fue norma esencial en su trabajo:

El desprecio de la diferencia o el matiz filosóficos es el defecto más característico del filosofar de Lenin. Baste con recordar las expeditivas identificaciones del pensamiento de Mach con el de Berkeley, o del de Bogdánov con el de Mach, en Materialismo y empiriocriticismo... La consecuencia más grave del vicio de desprecio del matiz filosófico es la falsedad de la argumentación, que se puede producir por verbalismo misoneísta o por provinciana ignorancia de las peculiaridades de ámbitos filosóficos o culturales diferentes de aquel en que vive o se ha formado el escritor.

Nunca él practicó el desprecio al matiz filosófico. Eso le permitió un desarrollo creativo del legado de la tradición. Entre sus propuestas renovadoras, una brilla con especial luz: sus reflexiones sobre una nueva política de la ciencia en la época del capitalismo desbridado.

\section{Propuestas para una politica socialista de la ciencia}

El núcleo de la posición de Sacristán en este ámbito de la política de la ciencia, campo no muy transitado ni abonado en el marxismo de aquellos años, como tampoco el de sus consecuencias para una reconstrucción del ideario comunista, puede resumirse en las tesis siguientes:

\section{$1^{\text {a }}$. Prioridad del enfoque ontológico.}

Para Sacristán, el filosofar metacientífico había discurrido básicamente por dos vías diferenciadas si bien no siempre excluyentes ${ }^{11}$ : la primera se había centrado en la relación entre ciencia y cultura, entre el conocer científico y la comprensión global del mundo y de la vida. A este tipo de consideraciones, las enmarcaba con el rótulo de "planteamiento o problemática epistemológica”. Existía otra línea de reflexión, cuyos antecedentes podían situarse en el idealismo alemán o incluso en Leibniz, que proponía considerar la relación entre la ciencia y la reflexión metacientífica, en términos más ontológicos. Heidegger era un representante destacado de esta segunda línea ${ }^{12}$. Consideraba Sacristán que el primer planteamiento era una línea que filosóficamente siempre estaría viva por la propia definición y autoconciencia del pensar y hacer científicos, que se sabe, o debería saberse, inseguro, revisable y limitado. Sin embargo, suponiendo y admitiendo que estas cuestiones fueran inextinguibles, él creía que tenían ya entonces una importancia secundaria, y que debían perder peso respecto a temáticas enmarcables en la metaciencia ontológica, dada la potencial y real peligrosidad de numerosas líneas de investi- 
gación de la tecnociencia contemporánea.

$2^{\mathrm{a}}$. Paralogismo de las concepciones neorrománticas.

Los peligros de la creciente y grave desorganización de la relación entre la especie humana y la naturaleza, fuertemente mediada por saberes y haceres científico-tecnológicos, habían facilitado un renacimiento de concepciones que agrupaba bajo la denominación de "filosofias románticas de la ciencia"13. Se refería a las corrientes emparentadas con el segundo Heidegger y con la literatura "contracultural" de los años sesenta y posteriores. Aun apreciando las emociones que subyacían en la crítica de estas corrientes y aun reconociendo el valor de algunos de sus análisis y descripciones, Sacristán rechazaba su menosprecio casi generalizado por el conocimiento operativo e instrumental, sosteniendo a un tiempo que no representaban una línea adecuada para salir del espeso bosque en el que nos encontrábamos inmersos. Entre otras razones, por el peligro de "impostura intelectual" que en ocasiones les afectaba: disertaban y sentenciaban sobre el conocimiento positivo hablando de asuntos que no eran, verdaderamente, la práctica científica realmente existente.

\section{$3^{\mathrm{a}}$. Contra el progresismo irrestricto.}

Fue en una conferencia impartida en la escuela de Ingenieros de Barcelona, cuando Sacristán empezó a referirse a la crisis que, en su opinión, acechaba tanto a la filosofía clásica de la ciencia como a las políticas científicas de carácter meramente progresista o desarrollista, defendidas por entonces con aquiescencia casi unánime. Esta situación de per- plejidad creciente afectaba directamente al corazón del progresismo clásico, a la fe progresista de que toda acumulación científica y todo avance tecnológico eran buenos en sí mismos. No había duda de que esta situación era netamente dependiente del carácter operacionalista de la ciencia moderna, del estrecho hermanamiento, cuando no identificación, entre la aventura de la ciencia y la empresa de la técnica. Él nunca sostuvo que fuera razonable una solución en negro que defendiera, sin más matices, una desvinculación de ambas y una consideración del ideal científico, con mirada estrictamente contemplativa, separado drásticamente del ámbito tecnológico. Y no sólo, aunque también, por lo que esta renuncia pudiera tener de irreal, sino porque, en su mirada, la práctica tecnológica era una parte imprescindible del avance científico ya que esa práctica era la que daba, en última instancia, intimidad al conocer.

$4^{\text {a }}$. Necesaria rectificación de las concepciones emancipatorias.

Las principales corrientes del marxismo habían pensado la ciencia moderna como neto factor de emancipación. El esquema clásico de la idea de revolución liberadora en la tradición era presentado por Sacristán en los términos siguientes: se partía de la hipótesis inductiva, de base histórica, de que situaciones de contraposición entre el crecimiento de las fuerzas productivas y las relaciones de producción que obstaculizaban ese crecimiento, junto con factores no fácilmente delimitables, constituían las condiciones de posibilidad de cualquier transformación, de lo que se infería, por lo que respecta a la política de la ciencia, un progresismo sin matices ni controles: la cien- 
cia era una fuerza productiva y toda política sensata de la ciencia, de orientación progresista y de izquierdas, tenía que consistir única y exclusivamente en su promoción. Cuanto más, mejor; cuanto menos, peor. De ahí una receta de la mayor simplicidad: había que asignar a la tecnociencia la mayor cantidad posible de recursos, no había ni debía haber más limitación que la de los recursos existentes. El esquema anterior era por de pronto inactual. Difícilmente un autor de la segunda mitad del XIX, como fue Marx, podía imaginarse la productividad del trabajo alcanzada a finales del XX. De lo que infería que la situación no permitía otorgar una fe incondicional a la manera tradicional de presentar este esquema de transformación social, mas teniendo en cuenta que el mismo Marx ya había considerado que en la época de la gran industria toda fuerza productiva era, al mismo tiempo, una fuerza destructiva.

La principal rectificación que los múltiples condicionamientos ecológicos suponían para el pensamiento revolucionario, en sus diferentes vertientes marxistas o libertarias, consistía ${ }^{14}$ en el abandono de todo milenarismo, de toda consideración de la revolución social como plenitud de los tiempos, ansiado momento a partir del cual obrarían, al fin, las buenas y objetivas leyes del Ser, deformadas hasta ese instante por las pecaminosas e injustas sociedades clasistas. No hay ni habrá paraíso terrenal. No hay ninguna sociedad humana pensable en la que se disuelvan o superen todas las contraposiciones sociales y naturales. No habrá Juicio Final, aunque desde luego haya sociedades más o menos alejadas de la idea de sociedad buena, como era el caso del modelo civilizatorio capitalista:
Mientras que los elementos del sistema son potencialmente de una gran racionalidad, su regulador, el mercado, presenta rasgos esenciales de irracionalidad. No sólo en su fase heroica, en el siglo XIX: en esa época su irracionalidad reside sobre todo en su imprevisibilidad incluso a plazo breve. El mercado de los tiempos heroicos del capitalismo se comporta con la a-racionalidad de la naturaleza: sólo funciona a fuerza de hecatombes. El mercado del bizantino capitalismo contemporáneo o monopolista revela su irracionalidad en lo que podría llamarse el "voluntarismo del mercado" o más corrientemente, "publicidad". Poderes caprichosos gobiernan ese mercado y a través de él, el cerebro de los hombres, influidos hasta en su modo de sentir y percibir por lo que se decide en las oficinas publicitarias de las grandes potencias del mercado, sin atender a más racionalidad que la maximización del beneficio privado.

$5^{\text {a }}$ Primacía del valor igualdad, control social de la investigación.

La política científica propuesta no tenía vocación de eternidad ni presuponía ni podía presuponer duración previa alguna y, en su opinión, debía estar sometida a revisión permanente. Se partía en ella de una primacía del valor igualdad sobre cualquier otro valor social, lo cual, obviamente, no implicaba anulación ni menosprecio alguno de otros valores, e implicaba, como decíamos, la necesidad de revisión de concepciones mayoritariamente 
aceptadas en las varias tradiciones emancipatorias. El asunto afectaba indudablemente a la libertad de investigación, pero no forzosamente más que las actuales restricciones. Admitiendo una corrección a la elección sin límites del científico investigador, valor que en la tecnociencia contemporánea era más una formulación de deseos que una realidad alcanzada, sostenía Sacristán que ese límite debía ser instrumentado de la forma más liberal y libertaria posible. Era probable que estas restricciones no fueran muy distintas de las realmente existentes, concretadas en una falta o en una disminución en la asignación de recursos a determinadas líneas de investigación o, por el contrario, primando ciertos programas en detrimento de otros, pero presentaban una diferencia esencial: Sacristán defendía que estas limitaciones, fueran sólo económicas o distributivas, o incluso político-culturales, para ser tolerables y admisibles ética y políticamente, tendrían que estar controladas por la propia colectividad, con presencia del mismo científico afectado o del colectivo investigador al que perteneciese.

\section{$6^{\text {a }}$ Por una dialecticidad temperada.}

Había, sin duda, en la propuesta defendida una politización del concepto de práctica pero no con la finalidad de primar o potenciar determinados programas de investigación por supuestas coincidencias ideológicas o político-filosóficas, sino en el sentido de orientar la investigación a determinadas áreas por sus probables aplicaciones prácticas, sociales, comunitarias, convirtiendo la salud laboral o la conservación del medio, por ejemplo, en tareas prioritarias de esta búsqueda sin término, pero no forzosamente sin finalidad, que es la ciencia.
El principio orientador general de esta política de la ciencia de inspiración socialista para esta federación de comunidades, como gustaba decir Sacristán en sus últimos años, exigía una rectificación de los modos de pensar hegelianos clásicos de algunas tradiciones marxistas. Defendía, pues, una dialecticidad que tuviera como primera virtud práctica el principio aristotélico de la mesura, fruto de la convicción de que las contraposiciones sociales eran de tal calibre que ya no podían considerarse resolubles al modo clásico hegeliano, por agudización del conflicto, sino mediante la postulación y creación de un marco en el que pudieran dirimirse sin catástrofe. No había pues que pensar en una solución en blanco y negro por el simple juego de supuestos factores objetivos, vía simplemente irrealizable o recusable sin más: recusable si se trababa de continuar y apostar por el simple desarrollismo económicotecnológico, dado que eso llevaría a la $\mathrm{Hu}-$ manidad al desastre; irrealizable, además de no deseable éticamente, si se optara, sin más, por el negro de la simple prohibición de la investigación:

En un mundo en el que nos aseguraran cierta garantía contra desmanes de las fuerzas productivas, pero a cambio de una prohibición de la investigación de lo desconocido, probablemente todos nos sublevaríamos, o por lo menos todos los filósofos que merecieran el nombre.

$7^{\mathrm{a}}$. Preeminencia de la educación de la ciudadanía.

Justificado este principio general, que él denominaba defensa de una "ética revolucionaria de la cordura”, Sacristán concretaba su 
propuesta programática de política de la ciencia en los siguientes puntos:

Había que admitir la preeminencia de la educación de la ciudadanía sobre la investigación durante un cierto largo período de tiempo de imposible concreción, cuya variabilidad dependería de las circunstancias sociales, históricas y culturales de las diferentes poblaciones. Esta primacía educacional estaba orientada a evitar malas reacciones, por ineducación de las colectividades, a las consecuencias que la línea defendida de política de la ciencia iba a conllevar inexorablemente. Entre ellas, una importante reducción del consumo, amén de una adecuada y mucho más justa redistribución del mismo. En todo caso, esta reducción no debía entenderse como simple anulación estoica de las necesidades. Inspirándose en el viejo Marx y en coincidencia con algunas tesis de Paul Lafargue, el traductor de El Capital consideraba que las necesidades que sentía un individuo son índice de su maduración, de su progreso vital, y que por ello cabía distinguir entre necesidades básicas y las de otro alcance.

Del punto anterior se colegía un corolario: la acentuación de la función educativa, formativa, de la enseñanza superior. Las facultades universitarias, todas ellas, deberían convertirse en centros donde, básicamente, se educase en los valores de una nueva sociedad. Esta medida, según el autor del "Manifiesto por una Universidad Democrática", significaría una menor "producción" de profesionales y un incremento en la producción de "hombres cultos", retomando la expresión de Ortega. Con ello, se produciría también un descenso del consumo, a través de la posible disminución de la productividad de bienes, por lo menos en una primera fase. $8^{a}$. Primacía de la investigación básica sobre la aplicada.

Proponía Sacristán además una línea de asignación de recursos que primase la investigación básica respecto a la aplicada, en oposición a las políticas científicas seguidas por la mayoría de gobiernos (no sólo occidentales) y, en algunos casos, reclamadas por importantes y poderosos colectivos de la sociedad civil. La justificación era, básicamente, la misma que la del punto anterior: repercusión negativa inmediata en el consumo y en la producción industrial de cierto tipo de bienes. De ahí la conveniencia de apoyar, en el trabajo de los colectivos científicos, los aspectos contemplativos respecto de los instrumentales, sin que ello implique, como decíamos, una vuelta imposible a la concepción contemplativa de la actividad científica, por lo demás siempre recordada por él con cierta nostalgia. Se trataría, por ejemplo, de contratar a muchos más físicos teóricos que a ingenieros físicos. Las razones, las mismas: reducción del producto final consumible.

También había que sostener la investigación de conocimiento directo descriptivo, no teórico. Para él, disciplinas menospreciadas en las universidades contemporáneas, como la Geografía o la Botánica descriptivas, eran buen saber para la época que se acercaba. Más aún: no sólo eran buen saber sino que, en algunos casos, podían ser mejor saber que el conocimiento teórico en su vertiente operativa. Había que disminuir igualmente los recursos dedicados a tecnología pesada y otorgar preeminencia a la inversión en tecnologías ligeras, más intensivas en fuerza de trabajo y menos en capital, más limpias ecológicamente y más sopor- 
tables por el medio. Investigación tecnológica que, por sus menores costes, en el sentido económico tradicional y en sentido social, estaría justificada aunque su ámbito de aplicación fuera más reducido que el de las tecnologías pesadas.

El objetivo central perseguido por esta última propuesta no sería tanto la disminución del producto final sino el aumento del tiempo colectivo de trabajo que evitara el creciente paro estructural, con sus secuelas sociales y culturales, aumento del tiempo de trabajo que, con toda seguridad, quedaría paliado si se eliminara la producción nociva y la enorme producción inútil existente, $\mathrm{y}$, en la concepción por él defendida si antes se hubiera dado la condición previa y básica de toda su propuesta: la sustitución de los antiguos poderes por otros de motivación igualitaria que intentaran, esta vez en serio, la superación de la vieja división social del trabajo.

9a . Actuación equilibrada en los países del "Tercer Mundo".

Sacristán se refirió también sucintamente a la problemática de las poblaciones del Tercer Mundo. Era obvio, que el tema del control demográfico había que tratarlo caso por caso. Parecía innegable su necesidad en el caso de países como China o India, pero era monstruosa la política maltusiana seguida por poderes y agencias norteamericanas entre la población amerindia en los años setenta del pasado siglo. Tampoco era defendible que fuera necesaria una reducción del consumo per capita en estas empobrecidas sociedades. Tenía que aumentar pero no tal como lo estaba haciendo, dado que en muchos de estos países la actuación de las multinacionales era simple y llanamente criminal. No había que intervenir con recetas preconcebidas pero tampoco pensando y defendiendo que determinadas industrias, rechazadas en las sociedades avanzadas, eran en cambio convenientes para aquellos países. Tampoco allí la contaminación, el peligro atómico o muchas de las actividades de alto riesgo relacionadas con la biotecnología o con las industrias químicas debían ser admitidas. Como no se cansó de denunciar, ésta era ya entonces la tendencia de muchas empresas del Norte "civilizado".

$10^{\mathrm{a}}$. Por una racionalidad completa.

Contraponiéndose matizadamente a posiciones como las defendidas por aquel entonces por Jesús Mosterín ${ }^{15}$, Sacristán no aceptaba la tesis de que fueran los técnicos quienes tuvieran el poder de decisión exclusivo sobre los denominados "problemas técnicos". Defender esa posibilidad era ignorar que también ellos, y los científicos, eran grupos humanos con intereses particulares, predispuestos a reaccionar frecuentemente según sus propios intereses. Era ingenuo pensar que el ciudadano-técnico iba a decidir siempre según los intereses generales de la comunidad. Esta posición no tenía en cuenta que los problemas sobre la técnica no son técnicos sino políticos, en el sentido general de forma de organización de la convivencia social. De ahí que los versos de Hölderlin reiteradamente citados y recordados por él ("De donde nace el peligro / nace la salvación también"), fueran interpretados en el sentido de que la actual situación de crisis, la contradictoriedad en la que nos encontramos inmersos, sólo puede disolverse o superarse a partir del uso de más razón, pero de razón compleja y con diversos registros, 
no de una razón meramente tecnocrática o estrechamente cientificista.

Su propuesta de racionalidad completa ${ }^{16}$ incluía el control democrático, social, sobre el desarrollo la ciencia. Si se construyera una fracción que arrojara la tasa de dominio de la ciudadanía sobre la ciencia en muchas sociedades capitalistas, su valor sería irrisorio. Pero, en cambio, no siempre había sido así ni estábamos condenados a seguir esa senda. En otras culturas, en la antigua civilización china por ejemplo, se habría obtenido una buena proporción, entre otras cosas, justo era reconocerlo, porque el denominador, la potencia científica de esa cultura, era bajo y era intenso el poder social sobre la ciencia. Incrementar esa fracción ya no iba a ser posible reduciendo el denominador, disminuyendo la fuerza de los saberes tecno-científicos. La única solución razonable pasaba por aumentar la fuerza de la ciudadanía, el poder social sobre la ciencia, el numerador de la fracción. De ahí, la importancia de la función educativa y del primado de la asignación de recursos a este ámbito en la propuesta programática por él defendida, sin negar que esa tarea no es un camino fácil dada la creciente complejidad y especialización de los conocimientos científicos contemporáneos, y aunque posiblemente no haya ningún tipo de control externo que pueda suplir el autocontrol de científicos y tecnólogos conscientes de su responsabilidad moral y social.

\section{Un poema en la pared de un calabozo fascista}

El marxismo del que fuera miembro del comité ejecutivo del PSUC fue un marxismocomunismo con declarada finalidad políti- ca revolucionaria socialista. Sin ismos pero rebosante de preguntas esenciales. Una de ellas, surgió a propósito de unos versos que vio arañados en la pared de una cárcel franquista, un calabozo de la Jefatura Superior de la Policía barcelonesa, donde Sacristán estuvo detenido ${ }^{17}$ :

[...] Shelley es el poeta seguramente más de izquierda de la tradición romántica inglesa, hasta extremos conmovedores. Una vez, al bajar a unos calabozos de la Jefatura Superior de Policía, en Barcelona, al cabo de un rato de estar sentado allí, me di cuenta que en una de las paredes algún preso había arañado, con las uñas, un verso de Shelley precisamente, y en inglés. No sé qué raro preso sería éste, pero el hecho es que allí estaba. No sé si con la democracia lo habrán quitado, cuando habría habido que ponerle un marco. Es un poema que dice: 'La luz del día,/ después de un estallido,/ penetrará al fin en esta oscuridad".

No hay marco, no hay versos, no hay recuerdo democrático de ello.

La propuesta anti-ideológica de Sacristán ("el pensamiento de Marx ha nacido como crítica de la ideología y su tradición no puede dejar de ser anti-ideológica sin desnaturalizarse"), ha escrito Francisco Fernández Buey, debe leerse propiamente como una advertencia: la recuperación teórica-práctica del marxismo no se hará mediante un nuevo retorno, volviéndose nuevamente hacia Hegel, sino mirando de frente a lo que hay, al presente, enlazando para ello con el conocimiento empírico, con el cultivo de las ciencias (naturales y sociales) positivas, con conocimientos populares y con praxis sociales creativas que no estén dispuestas a per- 
mitir que el peso y la voz de los explotadores siga tronando antihumanísticamente diez mil años más.

Un excelente Studium generale, un programa global y hasta un vivir general para todos los días de la semana, al que el editor de una de las primeras antologías ácratas en la España franquista añadía en su madurez una fuerte y sentida arista libertaria. Fue un marxista heterodoxo, radical, que quería ser austriaco - " si [...] hubiera que perder la nacionalidad por disidente, supongo que la primera que se me ocurriría pedir sería la austriaca... para poder tener que ver con Mozart"- y que amaba, "La flauta mágica":

El culturalismo pequeño-burgués no se da cuenta de la autocontradicción en que incurre: Mozart es tan pre-hombre como Robespierre. Por tanto, la prehumanidad es ya LA HUMANIDAD. Esa contradicción se debe al uso de ideas platónicas hegelianamente pseudohistorizadas. Pero en la actitud hay otro elemento de falsedad: el abusivo uso de 'sentido'. Sentido es algo que da la inserción en una estructura teleológica, principalmente la de la acción humana. Por eso tiene tanto sentido la acción de los estadistas como la de los artistas. Y hasta lo tiene más directamente. En cambio las entidades sueltas no tienen sentido. LA HUMANIDAD o LA VIDA no tienen sentido (= es un sinsentido afirmar que lo tengan y, en cambio, hace sentido metalingüístico decir que no lo tienen, pero significar que no se les puede atribuir). Ante la extinción de la humanidad, o incluso de las condiciones de la vida propia de este planeta, ¿qué "sentido" arquetípico tiene Die Zauberflöte (y es la pieza de música que más me importa en el mundo)?

La negativa a aceptar que los seres humanos son lo que son y como son, y que ya con ello había bastante para luchar contra tiranías y aberraciones sociales, concluía Sacristán, era "la base de todos las memeces y todas los desvaríos de los ideólogos progresistas.” Él no lo fue.

\section{REFERENCIAS BIBLIOGRÁFICAS}

Alba Rico, Santiago (2013), ¿Podemos seguir siendo de izquierdas? (Panfleto en símenor), Pol.len Ediciones, Barcelona.

Benach, Joan; Juncosa, X y López Arnal, S (eds, 2006). Del pensar, del vivir, del hacer. Barcelona, El Viejo Topo.

Capella, Juan-Ramón (2005): La práctica de Manuel Sacristán. Una biografia politica. Madrid, Trotta.

Capella, Juan-Ramón (1987), “Aproximación a la bibliografía de Manuel Sacristán Luzón”, Mientras tanto, n 30-31, pp. 193-223.

Capella, Juan-Ramón (1988), "Sobre la marginación de Manuel Sacristán”, Un ángel más, otoño de 1988, número 5, pp. 75-80.

Domènech, Antoni (2005), "Recuerdo de Manuel Sacristán, veinte años después”. El Viejo Topo, no 209-210, pp. 67-69.

Domingo Curto, Albert (2007). "Filosofía de una vida”. Introducción a Manuel Sacristán, Lecturas de filosofía moderna y contemporánea, op cit., pp. 9-41.

Fernández Buey, F. (1989), "El clasicismo de Manuel Sacristán”. Un Ángel más, ${ }^{\circ}$ 5, pp. 57-66.

Fernández Buey, F. (1991), La ilusión del método, Barcelona, Crítica. 
Fernández Buey, F. (1995). Presentación de Las ideas gnoseológicas de Heidegger, Barcelona, Crítica

Fernández Buey, F. (2013), Para la tercera cultura, Barcelona, El Viejo Topo.

Juncosa, Xavier (2006): Integral Sacristán. Barcelona, El Viejo Topo.

López Arnal, Salvador (2010). La destrucción de una esperanza. Manuel Sacristán y la primavera de Praga: lecciones de una derrota. Barcelona, Akal. Prólogo de Santiago Alba Rico.

López Arnal, Salvador (2013), Entre clásicos, Madrid, La oveja roja

López Arnal, S. y de la Fuente, P (1995, eds): Acerca de Manuel Sacristán, Barcelona, Destino.

López Arnal, S y Vázquez, Iñaki (eds, 2007). El legado de un maestro. Madrid, Papeles de la FIM.

Manzanera, Miguel (1991). "Teoría y práctica. La trayectoria intelectual de Manuel Sacristán". Tesis doctoral doctoral dirigida por José María Ripalda, UNED

Ovejero Lucas, Félix (2006): "Manuel Sacristán. Un marxista socrático”. Claves de la razón práctica, $\mathrm{n}^{\circ} 206$, junio 2006, pp. 46-55.

Pala, Giaime (2005), “ 'Sobre el camarada Ricardo'. El PSUC y la dimisión de Manuel Sacristán (1969-1970)", mientras tanto, $\mathrm{n}^{\mathrm{o}} 96$, otoño 2005, pp. 47-75.

Pala, Giaime (2009). Teoría, práctica militante y cultura política del PSUC (19681977). Tesis doctoral UPF. Director Francisco Fernández Buey

Sacristán, Manuel (1959). Las ideas gnoseológicas de Heidegger. Barcelona, Consejo Superior de Investigaciones Científicas (reedición: Crítica, 1995, a cargo de Francisco Fernández Buey).
Sacristán, Manuel (1964). Introducción a la lógica y al análisis formal. Ariel, Barcelona (varias reediciones).

Sacristán, Manuel (1975). Presentación, traducción, anotaciones y notas de traductor de S. M. Barrett (ed), Gerónimo. Historia de su vida. Barcelona, Grijalbo.

Sacristán, Manuel (1983), Sobre Marx y marxismo. Barcelona, Icaria.

Sacristán, Manuel (1984), Papeles de filosofia. Barcelona, Icaria.

Sacristán, Manuel (1985a), Intervenciones políticas. Barcelona, Icaria.

Sacristán, Manuel (1985b), Lecturas. Barcelona, Icaria

Sacristán, Manuel (1987), Pacifismo, ecología y política alternativa. Barcelona, Icaria (edición de Juan-Ramón Capella).

Sacristán, Manuel (1996). Lógica elemental. Barcelona, Vicens Vices (edición de Vera Sacristán Adinolfi; prólogo de Jesús Mosterín).

Sacristán, Manuel (1998). El orden y el tiempo. Madrid, Trotta. Edición de Albert Domingo Curto.

Sacristán, Manuel (2003). M.A.R.X. Máximas, aforismos y reflexiones con algunas variables libres. Barcelona, El Viejo Topo (edición de Salvador López Arnal, prólogo de Jorge Riechmann y epílogo de Enric Tello).

Sacristán, Manuel (2004b). De la primavera de Praga al marxismo ecologista. Entrevistas con Manuel Sacristán Luzón. Madrid, Los Libros de la Catarata (edición de Francisco Fernández Buey y Salvador López Arnal)

Sacristán, Manuel (2005), Seis conferencias. Sobre tradición marxista y los nuevos problemas. Barcelona, El Viejo Topo (presentación de F. Fernández Buey; 
epílogo de Manuel Monereo. Edición de Salvador López Arnal

Sacristán, Manuel (2007). Lecturas de filosofia moderna y contemporánea. Madrid, Trotta. Edición de Albert Domingo Curto. Sacristán, Manuel (2009). Sobre dialéctica. Mataró (Barcelona), El Viejo Topo. Edición de Salvador López Arnal

Sempere, Joaquim (1987): "Una semblanza personal, intelectual y política". mientras tanto 30-31, mayo 1987, pp. 5-31.

Tello, Enric (2005): “¿Fue Sacristán el primer marxista ecológico post-estalinista?'. El Viejo Topo, $\mathrm{n}^{\circ}$ 209-210, pp. 75-77.
Torres, Artemis y Machado Pasuch, Márcia Cristina, orgs (2013), Encontros com Paco Buey, EDUFMT, Cuiabá-MT.

Vega Reñón, L.(2005): "El lugar de Sacristán en los estudios de lógica en España", en López Arnal, S., Domingo Curto, A. y otros (eds), Donde no habita el olvido. Barcelona, Montesinos, pp. 19-49.

Documentación complementaria:

Archivo Histórico del Partido Comunista de España.

Biblioteca de la Facultad de Economía y Empresa de la Universidad de Barcelona [BFEEUB]

\section{NOTAS}

${ }^{1}$ Mientras tanto, $\mathrm{n}^{\circ}$ 63, otoño 1995, pp. 131-154.

${ }^{2}$ M. Sacristán, Sobre Marx y marxismo, Barcelona, Icaria, 1983, p. 133.

${ }^{3}$ Francisco Fernández Buey, "Marxismo y ecología en la obra de Manuel Sacristán”. FIM, Ateneo, Madrid, 17/II/2011, esquema. Será depositado en la Biblioteca UPF

${ }^{4}$ M. Sacristán, Papeles de filosofia, Barcelona, Icaria, 1984, pp. 381-410.

${ }^{5}$ Entre la documentación depositada en BFEEUB. Sobre este punto, Salvador López Arnal, La destrucción de una esperanza, Madrid, Akal, 2010.

${ }^{6}$ Archivo histórico del PCE. Igualmente, entre la documentación depositada en BFEEUB.

${ }^{7}$ Esta presentación, "La tarea de Engels en el AntiDühring", uno de sus textos clásicos, puede verse ahora en M. Sacristán, Sobre Marx y marxismo, op cit, pp. 24-51.

${ }^{8}$ Véase su voz de 1969 para el Diccionario de Filosofia editado por D. Runes en M. Sacristán, Papeles de filosofia, op cit, pp. 411-413.

${ }^{9} \mathrm{NH}, \mathrm{n}^{\mathrm{o}} 17,1969$, pp. 53-54.
${ }^{10}$ M. Sacristán, Sobre Marx y marxismo, op cit, pp. 133-175.

${ }^{11}$ M. Sacristán, Seis conferencias, Mataró (Barcelona), El Viejo Topo, 2005, pp. 55-81.

${ }^{12}$ La tesis doctoral de Sacristán estuvo centrada en la gnoseología del ex rector de Friburgo. M. Sacristán, Las ideas gnoseológicas de Heidegger, Barcelona, Crítica, 1995, edición y presentación de Francisco Fernández Buey.

${ }^{13}$ M. Sacristán, Papeles de filosofia, op cit, pp. 453455 .

${ }^{14}$ M. Sacristán, Pacifismo, ecologismo y política alternativa, Barcelona, Icaria, 1987 (edición de Juan-Ramón Capella), pp. 9-17, y M. Sacristán. Seis conferencias, op cit, pp. 73-81.

${ }^{15} \mathrm{~J}$. Mosterín, Racionalidad y acción humana, Madrid, Alianza editorial, 1977.

${ }^{16}$ M. Sacristán, "La función de la ciencia en la sociedad contemporánea”. Conferencia inédita. Trascripción de Salvador López Arnal.

${ }^{17}$ Cuaderno depositado en BFEEUB. 